\title{
Article \\ Evaluations of All-in-One, Polycarboxylate-Based Superplasticizer with Viscosity Modifying Agents for the Application of Normal-Strength, High-Fluidity Concrete
}

\author{
Tae-Woong Kong ${ }^{1}$, Hyun-Min Yang ${ }^{2, *}$, Han-Seung Lee ${ }^{3, *}$ a and Chang-Bok Yoon ${ }^{4}$ \\ 1 R\&D Center, Sunil Industrial Co., LTD, 68, Gwiin-ro, Dongan-gu, Anyang-si 14080, Korea; \\ genikong@sirmc.co.kr \\ 2 Innovative Durable Building and Infrastructure Research Center, Hanyang University, 1271 Sa 3-dong, \\ Sangnok-gu, Ansan-si 15588, Korea \\ 3 Department of Architectural Engineering, Hanyang University, 1271 Sa 3-dong, Sangnok-gu, \\ Ansan-si 15588, Korea \\ 4 Department of Architectural Engineering, Seoil University, 28-6, Yongmasan-ro 90-gil, Myeonmok, \\ Jungnang-gu, Seoul 02192, Korea; 20210009@seoil.ac.kr \\ * Correspondence: yhm04@hanyang.ac.kr (H.-M.Y.); ercleehs@hanyang.ac.kr (H.-S.L.)
}

check for

updates

Citation: Kong, T.-W.; Yang, H.-M.; Lee, H.-S.; Yoon, C.-B. Evaluations of All-in-One, Polycarboxylate-Based Superplasticizer with Viscosity Modifying Agents for the Application of Normal-Strength, High-Fluidity Concrete. Appl. Sci. 2021, 11, 11141. https://doi.org/10.3390/app112311141

Academic Editor:

Karin Habermehl-Cwirzen

Received: 23 September 2021

Accepted: 17 November 2021

Published: 24 November 2021

Publisher's Note: MDPI stays neutral with regard to jurisdictional claims in published maps and institutional affiliations.

Copyright: (C) 2021 by the authors. Licensee MDPI, Basel, Switzerland. This article is an open access article distributed under the terms and conditions of the Creative Commons Attribution (CC BY) license (https:// creativecommons.org/licenses/by/ $4.0 /)$.
Abstract: High fluidity concrete exhibits an excellent self-compacting property. However, the application of typical high-fluidity concrete is limited in the normal strength range (18 35 $\mathrm{MPa})$ due to the large amount of binder. Therefore, it is important to solve these problems by adding a viscosity modifying agent (VMA) with a superplasticizer (PCE), which helps to improve the fluidity of the concrete. In addition, the rheology and stability of the concrete with VMA can be improved by preventing bleeding and segregation issues. Current studies focused on the physical phenomena of concrete such as the fluidity, rheological properties, and compressive strength of normal-strength, high-fluidity concrete (NSHFC) with different types of a polycarboxylate-based superplasticizer (NPCE). The obtained results suggested that the combinations of all-in-one polycarboxylate-based superplasticizers (NPCE) did not cause any cohesion or sedimentation even stored for a long time. The combination of three types of VMA showed the best fluidity (initial slump flow of 595 630 mm) without any segregation and bleeding, and the compressive strength at 28 days was also found to be the highest: $34-37 \mathrm{MPa}$. From these results, the combination of PCE $(2.0 \%)+$ HPMC $(0.3 \%)+$ WG $(0.1 \%)+$ ST $(0.1 \%)$ showed an $18 \%$ higher plastic viscosity and $-4.4 \%$ lower yield stress than Plain.

Keywords: polycarboxylate-based superplasticizer; normal-strength; high-fluidity concrete; viscosity; rheology; workability

\section{Introduction}

High-fluidity concrete flows under its own weight, filling formwork, and achieves a full compaction, even in the presence of congested reinforcement. Improvement in construction quality and efficiency, shortening the construction time, and reducing labor costs were considered advantages of the high-fluidity concrete that should be highlighted [1]. However, high-fluidity concrete is affected by the rheology and thixotropy of cementitious materials. Therefore, there is a large difference in the properties depending on the contents of binders such as cement and mineral admixtures, and the particle size of the aggregate [2]

Most researchers applied a large amount of binder and expensive admixtures to develop self-compacting or high-fluidity concrete [3-8]. Moreover, many researchers are used smaller-sized coarse aggregates (maximum size of $20 \mathrm{~mm}$ or $25 \mathrm{~mm}$ ) or used fine aggregates at the level of fine fillers $[9,10]$.

In order to expand the range of the applications of high-fluidity concrete, it is necessary to secure the stability properties of the concrete with good fluidity, viscosity, and appropriate strength. The stability of the fresh properties of the fluidity concrete is determined by 
several parameters including particle and fluid movement. The stability of concrete can be classified into the separation and sedimentation of coarse aggregate and cement paste in concrete, as well as the bleeding of concrete [11-13]. In particular, to produce normal strength concrete with a high fluidity and low binder content, the yield stress must be minimized while securing plastic viscosity [14-16]. For this, the filling ability with the high dispersion effect of the superplasticizer should be utilized $[17,18]$. However, there was a limitation in ensuring the high workability, strength, and durability of conventional, polycarboxylate-based superplasticizer concrete with a normal strength and a low amount of binder.

These problems can be solved by adding VMA and PCE to help improve the fluidity of the concrete by the improved filling and dispersion ability of the binders $[19,20]$. In addition, the rheology and stability of the concrete with VMA can be improved by preventing bleeding and segregation problems. VMA improves the retention of cement paste components in the suspension [21], cohesion, stability, and viscosity of the concrete. Therefore, the rheology and stability of the concrete with VMA can be improved by preventing bleeding and segregation problems [22-25]. Moreover, it can replace mineral admixtures such as fly ash and silica fumes [19].

Among the most popular VMAs, hydroxypropyl-methylcellulose (HPMC), welan gum, guar gum, and starch have excellent thickening, adhesive, and water retention properties, and are widely used in construction as an additive to concrete or mortar. HPMC has good adhesive, thickening, and water retention properties, and is mainly applied in self-leveling mortar and self-compacting concrete, with the intention of improving bleeding and aggregate segregation $[26,27]$. Welan gum is widely applied to prevent the bleeding and segregation of mortar or concrete, as well as at higher $\mathrm{W} / \mathrm{C}$ ratios, and less additive is needed $[28,29]$. Guar gum improves the water retention of mortar or concrete, adapts the rheological behavior of the cementitious materials, prevents aggregate segregation and improves the workability and homogeneity of cement-based systems. Moreover, the addition of the guar gum slightly increases the strength and reduces the carbonation rate $[30,31]$. Starches are VMA that alter the properties of a mortar in the fresh state. They improve the viscosity and homogeneity of a material in mortars and concretes, and are often used together with a high-range, water-reducing admixture to avoid segregation and bleeding and to improve the cohesion of a mortar or concrete [22,24].

Despite the many advantages of VMA in concrete or mortar, if PCE and VMA are mixed and stored, then there is issue of productivity, usability, and storage in ready-mixed concrete plants [32].

The above literature search suggests that there are no such studies on the mixing of allin-one, polycarboxylate-based superplasticizers (NPCE) that did not cause any cohesion or sedimentation even when PCE and VMA were mixed and stored for a long time. Therefore, in the present studies, an all-in-one, polycarboxylate-based superplasticizer, with viscosity modifying agents for the application of normal-strength, high-fluidity con-crete, mixed and evaluated the properties of this concrete.

\section{Materials and Methods}

\subsection{Materials}

\subsubsection{Cement and Mineral Admixtures}

Type 1 Portland cement (ASTM C 150) was used with a density and fineness of $3.15 \mathrm{~g} / \mathrm{cm}^{3}$ and $3590 \mathrm{~cm}^{2} / \mathrm{g}$, respectively [33]. Mineral admixtures of fly ash and blast furnace slag were used in accordance with KSL 5405 [34] and KS F 2563 [35], respectively. The density of fly ash and blast furnace slag was $2.24 \mathrm{~g} / \mathrm{cm}^{3}$ and $2.90 \mathrm{~g} / \mathrm{cm}^{3}$, while fineness was $3350 \mathrm{~cm}^{3} / \mathrm{g}$ and $4130 \mathrm{~cm}^{3} / \mathrm{g}$, respectively. Table 1 shows the physical and chemical properties of cement, fly ash, and blast furnace slag. 
Table 1. Physical and chemical properties of cement, fly ash, and blast furnace slag.

\begin{tabular}{ccccc}
\hline & & \multicolumn{3}{c}{ Contents (wt.\%) } \\
\cline { 3 - 5 } & & Cement & Fly Ash & $\begin{array}{c}\text { Blast Furnace } \\
\text { Slag }\end{array}$ \\
\hline Physical & Density $\left(\mathrm{g} / \mathrm{cm}^{3}\right)$ & 3.15 & 2.24 & 2.90 \\
properties & Blaine $\left(\mathrm{cm}^{2} / \mathrm{g}\right)$ & 3590 & 3350 & 4130 \\
\hline & $\mathrm{CaO}$ & 62.51 & 3.12 & 42.11 \\
& $\mathrm{SiO}_{2}$ & 21.46 & 55.59 & 31.86 \\
Chemical & $\mathrm{Al}_{2} \mathrm{O}_{3}$ & 6.44 & 23.54 & 14.43 \\
properties & $\mathrm{SO}_{3}$ & 2.32 & 0.41 & 2.12 \\
& $\mathrm{Fe}_{2} \mathrm{O}_{3}$ & 3.03 & 7.79 & 0.75 \\
& $\mathrm{MgO}$ & 2.75 & 1.20 & 3.81 \\
& $\mathrm{Ig} . \operatorname{loss}(\%)$ & $1.21\left(950 \pm 50{ }^{\circ} \mathrm{C}\right)$ & $1.81\left(975 \pm 25^{\circ} \mathrm{C}\right)$ & $0.56\left(700 \pm 2{ }^{\circ} \mathrm{C}\right)$ \\
\hline
\end{tabular}

\subsubsection{Aggregates}

In this study, $20 \mathrm{~mm}$ coarse aggregates (gravel) and fine aggregates (sea sand) were used in accordance with KS F 2527 [36]. The density was found to be at $2.69 \mathrm{~g} / \mathrm{cm}^{3}$ and $2.58 \mathrm{~g} / \mathrm{cm}^{3}$, with a fineness modulus of 6.61 and 2.12, respectively. Table 2 shows the physical properties of the aggregates used.

Table 2. Physical properties of aggregate.

\begin{tabular}{ccc}
\hline & Fine Aggregate & Coarse Aggregate \\
\hline Density $\left(\mathrm{g} / \mathrm{cm}^{3}\right)$ & 2.58 & 2.69 \\
Fineness modulus & 2.12 & 6.64 \\
Water absorption ratio $(\%)$ & 0.86 & 0.53 \\
Passing ratio of 0.08 mm sieve (\%) & 2.95 & 0.77 \\
\hline
\end{tabular}

\subsubsection{Superplasticizer}

In order to apply to NSHFC, PCE is used and developed in advance. In the present study, the fluidity and rheological properties were reviewed according to three types of combinations of MPEG-type polycarboxylate ether (water reduction type, hybrid type, retention type).

Table 3 shows the appearances and functional characteristics of each type of raw material.

Table 3. Properties of PC-based raw materials.

\begin{tabular}{|c|c|c|}
\hline Types & Appearances & Description \\
\hline $\begin{array}{l}\text { Water } \\
\text { reduction type }\end{array}$ & $\begin{array}{l}\text { Light yellow } \\
\text { liquid }\end{array}$ & $\begin{array}{l}\text { - } \quad \begin{array}{l}\text { Excellent water reduction by the powerful } \\
\text { dispersing effect }\end{array} \\
\text { - } \quad \text { High flowable concrete }\end{array}$ \\
\hline Hybrid type & $\begin{array}{l}\text { Yellowish-brown } \\
\text { liquid }\end{array}$ & $\begin{array}{l}\text { - } \quad \text { High water reduction and long slump retention } \\
\text { - Good for blending cement (fly ash, blast } \\
\text { furnace slag) } \\
\text { - } \quad \text { Higher compressive strength at an early age and } \\
\text { 28 days } \\
\text { - } \quad \text { High workability without bleeding or segregation }\end{array}$ \\
\hline Retention type & Faint light yellow & Excellent water reduction and long slump retention \\
\hline
\end{tabular}




\subsubsection{VMA (Viscosity Modifying Agent)}

In this study, hydroxypropyl methylcellulose (HPMC (HL, HH)), starch (ST), welan gum (WG), and guar gum (GG) were dissolved in distilled water and used as VMAs. The appearance, physical, and chemical properties of the VMAs are presented in Table 4 .

Table 4. Appearance and chemical composition of VMAs.

\begin{tabular}{ccccc}
\hline & HPMC & WG (Welan Gum) & GG (Guar Gum) & ST (Starch) \\
\hline & & & & \\
Appearance & & & & \\
& & & & \\
Phase & Liquid & Liquid & Liquid & Liquid \\
Color & Light brown & Medium opaque & Dark brown & Light opacity \\
Molecular & 324.3 & 168.2 & 535.2 & 342.3 \\
weight (g/mol) & 55,500 (sol.2\%) & 15,300 (sol.2\%) & $4700($ sol.2\%) & 7900 (sol.5\%) \\
Viscosity (cps) & 1.210 & 1.460 & 1.246 & 1.466 \\
Specific gravity & $1.2 \pm 1$ & $7 \pm 1$ & $7 \pm 1$ & $11 \pm 1$ \\
pH & $7 \pm 1$ & $7 \pm 1$ & &
\end{tabular}

\subsection{Experimental Methods}

\subsubsection{Preparation of the Polycarboxylate-Based Superplasticizers (NPCE)}

Polycarboxylate-based superplasticizers (NPCE) were prepared by mixing VMA and PCE. All NPCE solutions were mixed for $10 \mathrm{~min}$ at $1000 \mathrm{rpm}$ using a homogenizer (Figure 1a). Then, the solution was further mixed for another $6 \mathrm{~h}$ at $300 \mathrm{rpm}$ using a magnetic stirrer (Figure 1b) for stabilization purposes. The mixed proportion of the NPCE solution was presented in Table 5.

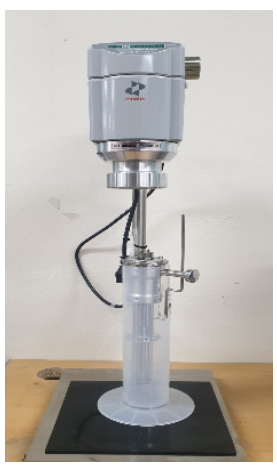

(a)

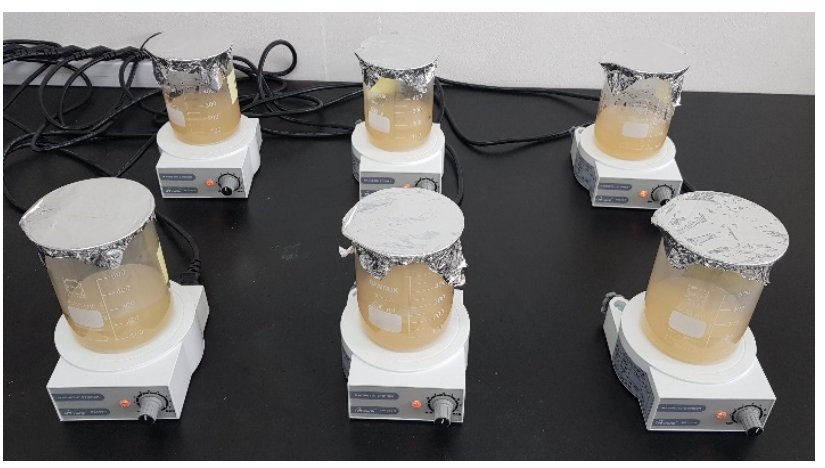

(b)

Figure 1. Mixing equipment for manufacturing NPCE. (a) homogenizer, (b) magnetic stirrers.

\subsubsection{Concrete Mix}

The concrete mixing was performed using a pen-type mixer (WOOJIN, WJ-226, Gyeonggi-do, South Korea). First, aggregates and binders were mixed at $25 \mathrm{rpm}$ for $60 \mathrm{~s}$. Next, NPCE solution and water were added and mixed at $35 \mathrm{rpm}$ for another $180 \mathrm{~s}$. Then, the concrete mix was poured into the cylindrical concrete mold of size $100 \mathrm{~mm} \times 200 \mathrm{~mm}$. The concrete samples were cured for 1 day at $20 \pm 2{ }^{\circ} \mathrm{C}$ before being de-molded and kept in the water tank for another 27 days of curing duration. Table 5 shows the mixed proportion of the normal-strength, high-fluidity concrete. 
Table 5. Combinations of NPCE and mixture design for NSHFC.

\begin{tabular}{|c|c|c|c|c|c|c|c|c|c|c|c|c|c|}
\hline & \multicolumn{2}{|c|}{$\%$} & \multicolumn{5}{|c|}{$\mathrm{kg} / \mathrm{m}^{3}$} & \multicolumn{6}{|c|}{ NPCE (Binders $\times$ wt.\%) } \\
\hline & \multirow{2}{*}{ W/B } & \multirow{2}{*}{ S/a } & \multirow{2}{*}{ W } & \multicolumn{3}{|c|}{ Binders } & \multirow{2}{*}{$\mathbf{S}$} & \multirow{2}{*}{ G } & \multirow{2}{*}{ PCE } & \multirow{2}{*}{ HPMC } & \multirow{2}{*}{ WG } & \multirow{2}{*}{ GG } & \multirow{2}{*}{ ST } \\
\hline & & & & $\mathrm{C}$ & FA & BS & & & & & & & \\
\hline Plain & 43.5 & 55.0 & 152 & 228 & 53 & 70 & 983 & 811 & 2.0 & & & & \\
\hline HL & & & & & & & & & 2.0 & 0.3 & - & - & - \\
\hline $\mathrm{HH}$ & & & & & & & & & 2.0 & 0.6 & - & - & - \\
\hline WG & 43.9 & 55.0 & 154 & 228 & 53 & 70 & 981 & 809 & 2.0 & - & 0.1 & - & - \\
\hline GG & & & & & & & & & 2.0 & - & - & 0.1 & - \\
\hline ST & & & & & & & & & 2.0 & - & - & - & 0.1 \\
\hline HLW & & & & & & & & & 2.0 & 0.3 & 0.1 & - & - \\
\hline HHW & 44.3 & 55.0 & 155 & 228 & 53 & 70 & 979 & 807 & 2.0 & 0.6 & 0.1 & - & - \\
\hline HLWG & & & & & & & & & 2.0 & 0.3 & 0.1 & 0.1 & - \\
\hline HLWS & & & & & & & & & 2.0 & 0.3 & 0.1 & - & 0.1 \\
\hline HHWG & 45.6 & 55.0 & 160 & 228 & 53 & 70 & 973 & 802 & 2.0 & 0.6 & 0.1 & 0.1 & - \\
\hline HHWS & & & & & & & & & 2.0 & 0.6 & 0.1 & - & 0.1 \\
\hline
\end{tabular}

C: cement, FA: fly ash, BS: blast furnace slag, S: fine aggregate, G: coarse aggregate, HPMC: hydroxypropyl methylcellulose, WG: welan gum, GG: guar gum, and ST: starch.

\subsubsection{Fluidity}

In accordance with ASTM C 1611, the slump flow test was conducted to evaluate the workability of the NSHFC. The workability value was measured by two orthogonal parts (longest length and shortest length) and the average value of both measurements was taken.

\subsubsection{Rheology}

To measure the rheology of NSHFC, rotational viscometer (BROOKFIELD, DV-III ULTRA, Middleborough, MA, USA) coupled with spindle SC4-29 was used. The concrete sample was crushed, and the mortar sample was collected. The shear rate was changed at each step to measure the torque, with values of $0.125,0.25,0.625,1.25,2.5,5,12.5$, and $25 \mathrm{~s}^{-1}$. The consistency curve was derived by applying the Bingham model Equation (1), and the plastic viscosity and yield stress were calculated by linear regression analysis:

$$
\tau=\tau^{\circ}+n_{\gamma} \lambda
$$

where $\tau$ is the shear stress $(\mathrm{Pa}), \tau^{\circ}$ is the yield stress $(\mathrm{Pa}), n_{\gamma}$ is the plastic viscosity (Pa s), and $\lambda$ is the shear rate $\left(\mathrm{s}^{-1}\right)$.

\subsubsection{Compressive Strength}

The compressive strength test was carried out according to ASTM C39 [37]. Cylindrical concrete specimens of size $100 \mathrm{~mm} \times 200 \mathrm{~mm}$ were used and tested after 3,7 , and 28 days of curing duration [38].

\section{Results and Discussion}

\subsection{Workability}

Figure 2 shows the workability properties of concrete according to the combination of PCE and VMA, and Table 6 shows the shapes of the slump flow. With the addition of PCE without VMA, the slump flow is found to be at $555 \mathrm{~mm}$ and $523 \mathrm{~mm}$ at the start of the experiment and after $60 \mathrm{~min}$, respectively. From our observation, segregation occurs in the middle of the samples even after $60 \mathrm{~min}$ of testing. Moreover, the addition of PCE with only one type of VMA (HL, HH, WG, GG, and ST) shows the largest slump flow at the initial time for the ST sample (693 mm) followed by HL (660 mm), GG (600 mm), and HH and WG (548 mm). After 60 min of testing, ST shows the lowest elapsed ratio of slump flow $(4.3 \%)$ followed by HH (4.6\%), HL (6.1\%), GG (7.9\%), and WG (24.7\%). WG shows a high plastic viscosity and yield stress by strengthening the cohesion of the cement particles. 
Due to the smaller slump value of the WG samples, segregation does not occur. In the case of adding PCE with HL, ST, or GG, the slump value is over $600 \mathrm{~mm}$, with the occurrence of segregation. In particular, ST shows the highest slump flow value, but shows the most severe segregation. This is caused by the lowest plastic viscosity and yield stress. Thus, it is confirmed that there is a limit in securing the fluidity and segregation resistance when only one type of VMA is added.

Aside from this, with the addition of PCE with two types of VMA (HLW and HHW), the initial slump flows are found to be $543 \mathrm{~mm}$ and $540 \mathrm{~mm}$ for HLW and HHW samples, respectively. After 60 min of testing, the elapsed ratio of slump flow was larger in HLW samples $(17.1 \%)$ compared to HHW samples $(7.9 \%)$. It was expected that, with the increase in the amount of HPMC (0.3 to $0.6 \%)$, the adsorption disturbance of the PCE will increase, and the dispersion of cement particles will decrease.

Furthermore, with the addition of PCE with three types of VMA (HLWG, HLWS, HHWG, and HHWS), the initial slump flow of HLWS is the largest $(630 \mathrm{~mm})$, followed by HLWG and HHWS (613 mm), and HHWG (595 mm). After 60 min of testing, the elapsed ratio of slump flow is the lowest for HHWS (3.7\%), followed by HHWS (6.3\%), HHWG $(11.3 \%)$, and HLWG (14.7\%). The increase in the amount of HPMC decreases the elapsed ratio due to the characteristics of the HPMC, which will delay the setting time of the cement paste. On the other hand, in the case of the HH (HPMC 0.6\%) combination, segregation does not occur due to the slump flow value.

In summary, when the amount of HPMC increases from $0.3 \%$ to $0.6 \%$, the cohesion of the concrete is strengthened. This causes an increase in the plastic viscosity and yield stress of the concrete and reduces the slump flow. The elapsed ratio decreases because HPMC enhances the water retention and delays the setting time of concrete. Generally, regardless of the amount and combinations of HPMC, ST has an effect on increasing fluidity and reducing the elapsed ratio. WG has an effect on reducing fluidity and increasing the elapsed ratio. These results are similarly reflected in all combinations of VMAs. Additionally, ST increases fluidity more than GG. Because of this effect, the tendency of the slump flow increases slightly.

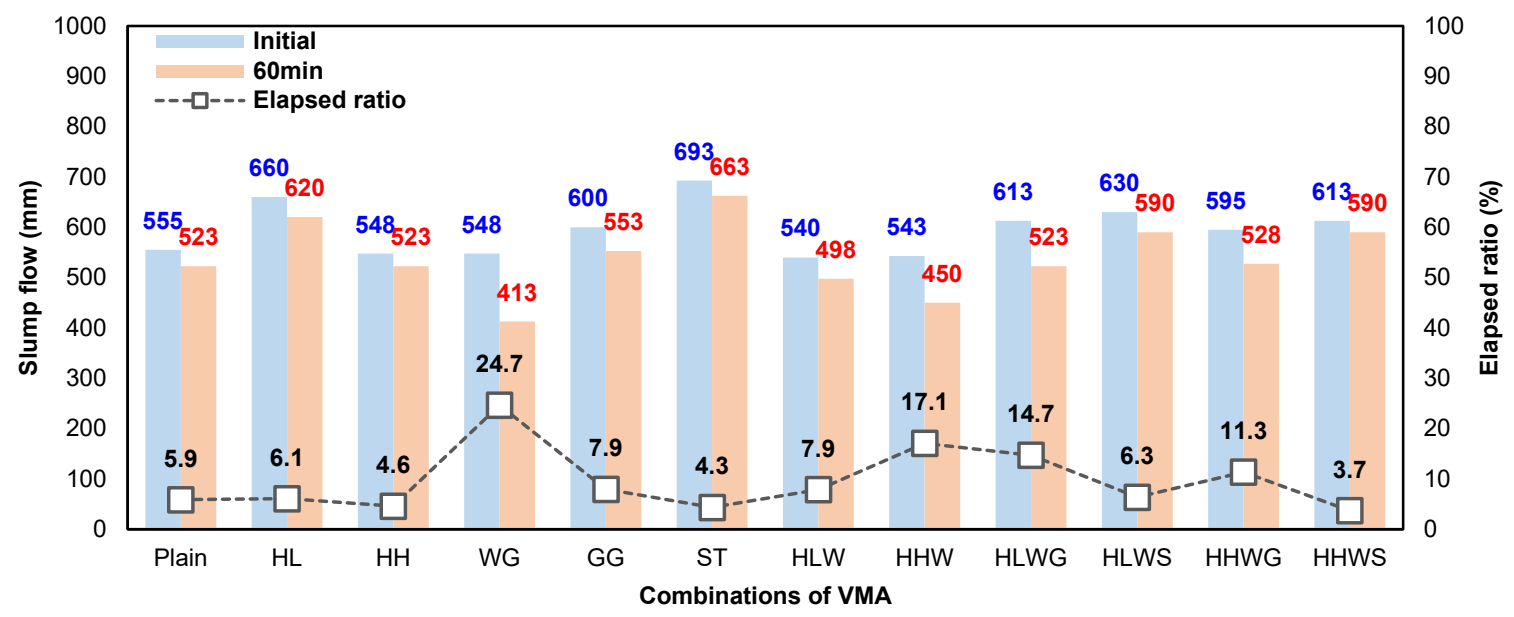

Figure 2. Slump flow and elapsed ratio of fresh concrete mixes by combinations of VMAs. Plain: non-VMA, HL: HPMC $0.3 \%$ only, HH: HPMC $0.6 \%$ only, WG: welan gum only, GG: guar gum only, ST: starch only, HLW: HPMC $(0.3 \%)+$ welan gum $(0.1 \%)$, HHW: HPMC $(0.6 \%)+$ welan gum $(0.1 \%)$, HLWG: HPMC $(0.3 \%)+$ welan gum $(0.1 \%)+$ guar gum $(0.1 \%)$, HLWS: HPMC $(0.3 \%)+$ welan gum $(0.1 \%)+$ starch $(0.1 \%)$, HHWG: HPMC $(0.6 \%)+$ welan gum $(0.1 \%)+$ guar gum $(0.1 \%)$, HHWS: HPMC $(0.6 \%)+$ welan gum $(0.1 \%)+\operatorname{starch}(0.1 \%)$. 
Table 6. Appearance of slump flow fresh concrete mixes by combinations of VMAs.

\begin{tabular}{|c|c|c|c|c|c|c|}
\hline & Plain & HL & $\mathbf{H H}$ & WG & GG & ST \\
\hline \multicolumn{7}{|l|}{ Initial } \\
\hline & $\begin{array}{c}565 \mathrm{~mm} \times 545 \\
\mathrm{~mm}\end{array}$ & $\begin{array}{c}660 \mathrm{~mm} \times 660 \\
\mathrm{~mm}\end{array}$ & $\begin{array}{c}540 \mathrm{~mm} \times 555 \\
\mathrm{~mm}\end{array}$ & $\begin{array}{c}555 \mathrm{~mm} \times 540 \\
\mathrm{~mm}\end{array}$ & $\begin{array}{c}600 \mathrm{~mm} \times 600 \\
\mathrm{~mm}\end{array}$ & $\begin{array}{c}695 \mathrm{~mm} \times 690 \\
\mathrm{~mm}\end{array}$ \\
\hline \multicolumn{7}{|l|}{$60 \mathrm{~min}$} \\
\hline & $\begin{array}{c}555 \mathrm{~mm} \times 490 \\
\mathrm{~mm}\end{array}$ & $\begin{array}{c}620 \mathrm{~mm} \times 620 \\
\mathrm{~mm}\end{array}$ & $\begin{array}{c}530 \mathrm{~mm} \times 515 \\
\mathrm{~mm}\end{array}$ & $\begin{array}{c}415 \mathrm{~mm} \times 410 \\
\mathrm{~mm}\end{array}$ & $\begin{array}{c}565 \mathrm{~mm} \times 540 \\
\mathrm{~mm}\end{array}$ & $\begin{array}{c}670 \mathrm{~mm} \times 655 \\
\mathrm{~mm}\end{array}$ \\
\hline & HLW & HHW & HLWG & HLWS & HHWG & HHWS \\
\hline \multirow[t]{2}{*}{ Initial } & & & & & & \\
\hline & $\begin{array}{c}550 \mathrm{~mm} \times 535 \\
\mathrm{~mm}\end{array}$ & $\begin{array}{c}550 \mathrm{~mm} \times 530 \\
\mathrm{~mm}\end{array}$ & $\begin{array}{c}615 \mathrm{~mm} \times 610 \\
\mathrm{~mm}\end{array}$ & $\begin{array}{c}635 \mathrm{~mm} \times 625 \\
\mathrm{~mm}\end{array}$ & $\begin{array}{c}615 \mathrm{~mm} \times 575 \\
\mathrm{~mm}\end{array}$ & $\begin{array}{c}615 \mathrm{~mm} \times 610 \\
\mathrm{~mm}\end{array}$ \\
\hline \multicolumn{7}{|l|}{$60 \mathrm{~min}$} \\
\hline & $\begin{array}{c}465 \mathrm{~mm} \times 435 \\
\mathrm{~mm}\end{array}$ & $\begin{array}{c}500 \mathrm{~mm} \times 495 \\
\mathrm{~mm}\end{array}$ & $\begin{array}{c}530 \mathrm{~mm} \times 515 \\
\mathrm{~mm}\end{array}$ & $\begin{array}{c}590 \mathrm{~mm} \times 590 \\
\mathrm{~mm}\end{array}$ & $\begin{array}{c}530 \mathrm{~mm} \times 525 \\
\mathrm{~mm}\end{array}$ & $\begin{array}{c}590 \mathrm{~mm} \times 590 \\
\mathrm{~mm}\end{array}$ \\
\hline
\end{tabular}

\subsection{Rheological Performance}

Figures 3 and 4 show the consistency curve of the fresh concrete added with NPCE prepared by VMA combinations at an initial time and after $60 \mathrm{~min}$, respectively. The plastic viscosity and yield stress are derived by applying the Bingham model to these results. Moreover, the plastic viscosity and yield stress of the fresh concrete are depicted in Figures 5 and 6, respectively. With the addition of only PCE (plain), the plastic viscosity is found to be at 1.11 Pa s at the start time and 1.21 Pa s after $60 \mathrm{~min}$ of testing. Moreover, the yield stress is found to be at 2.89 Pa at an initial time and $3.45 \mathrm{~Pa}$ after $60 \mathrm{~min}$ of testing. With the addition of PCE with one type of VMA (HL, HH, WG, GG, and ST), the plastic viscosity of WG samples is the highest, followed by GG, HH, HL, and ST. Moreover, the yield stress of WG samples is also the highest compared to other types of VMAs. It shows that WG is strongly adsorbed onto cement particles, and this adsorption could be the reason for the increase in the yield stress due to bridging flocculation. In particular, when ST is added, the plastic viscosity value is found to be similar to the plain sample, but the yield stress is reduced. Due to this, slump flow is improved, but shows a more severe segregation.

With the addition of PCE with two types of VMA (HLW and HHW), plastic viscosity and yield stress of the HHW sample are higher compared to the HLW sample. It is considered that the viscosity of concrete increased as the amount of HPMC increased from $0.3 \%$ to $0.6 \%$.

With the addition of PCE with three types of VMA (HLWG, HLWS, HHWG, and HHWS), the plastic viscosity and yield stress of HHWG are the highest, followed by 
the HLWS, HHWG and HHWS sample. It is considered that the combinations of GG increased the plastic viscosity of concrete more than with the combinations of ST, because the cohesion of GG is stronger than that of ST in cement paste. In summary, adding VMA shows a higher plastic viscosity when compared to plain samples [39-42]. The plastic viscosity and yield stress show a proportional relationship regardless of the combinations of VMA and the elapsed time. Moreover, the plastic viscosity and yield stress decrease when the slump flow is increased and vice versa. An inverse relationship is found between the plastic viscosity or yield stress and the slump flow [43].

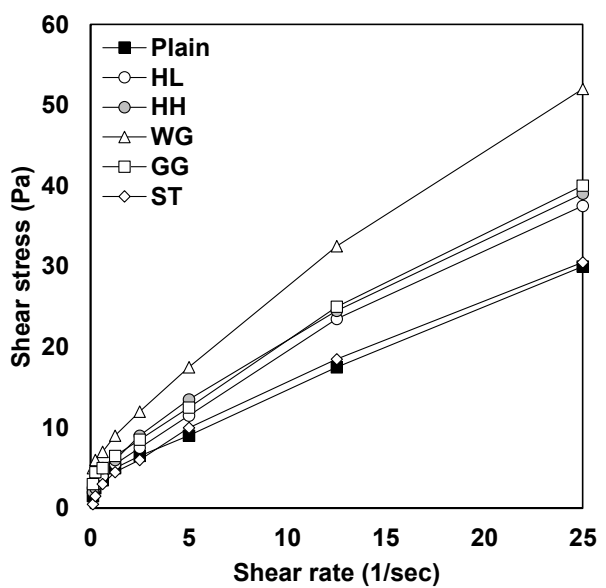

(a)

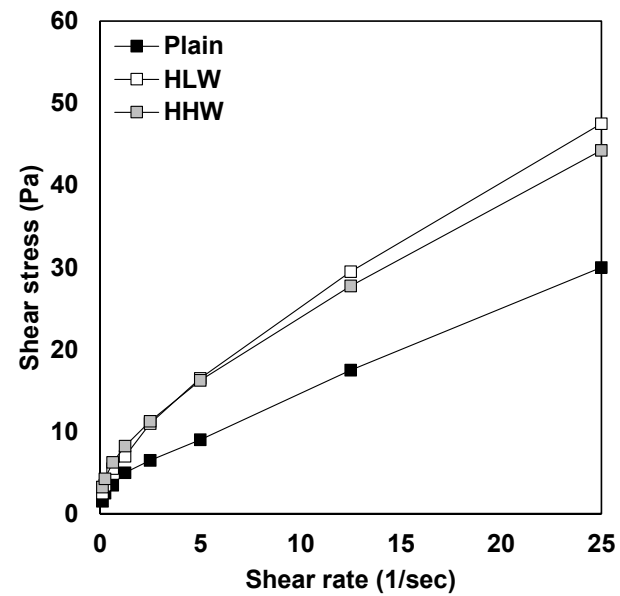

(b)

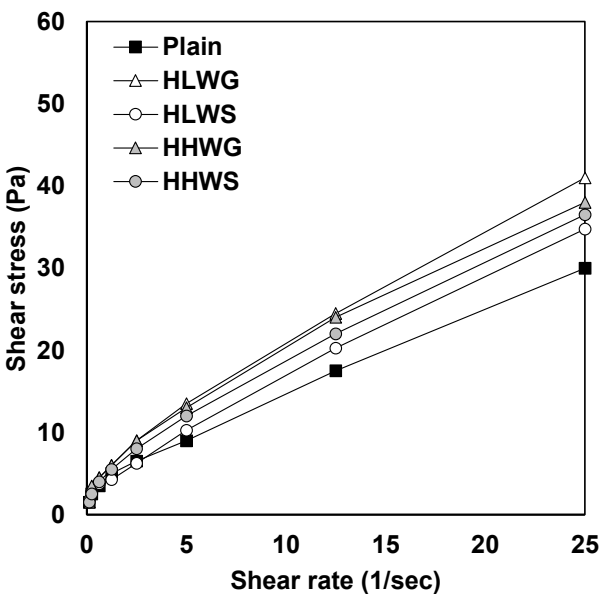

(c)

Figure 3. Consistency curves of fresh concrete added with NPCE prepared by VMA combinations at the initial time. (a) Combinations of one type of VMA only. (b) Combinations of two types of VMAs. (c) Combinations of three types of VMAs. 


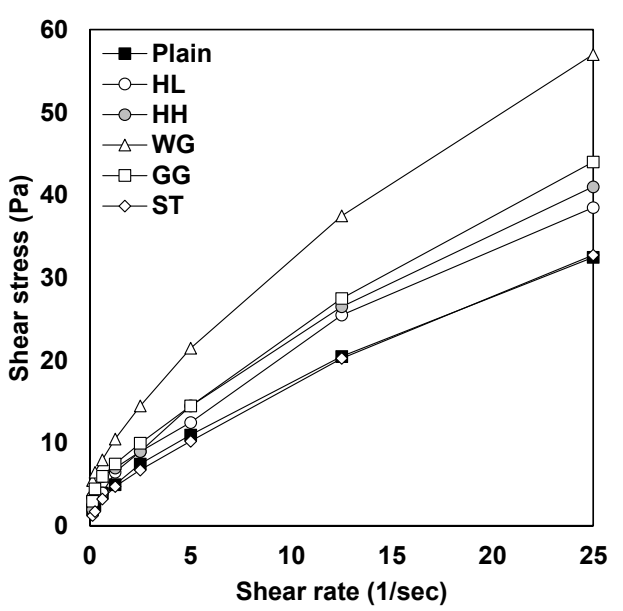

(a)

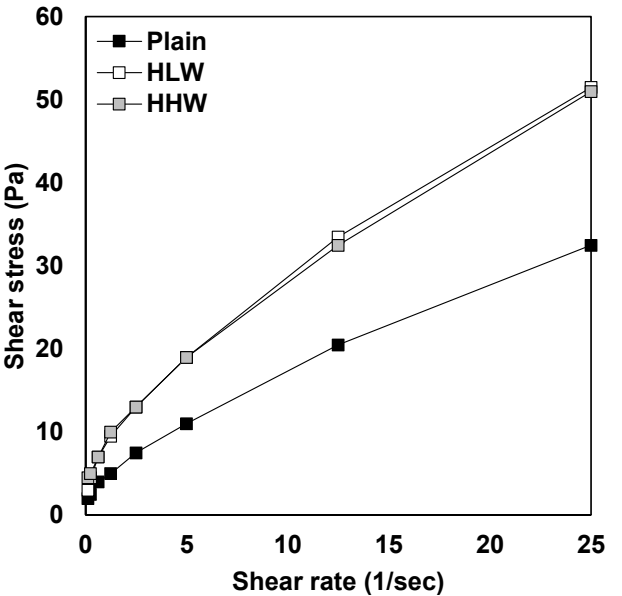

(b)

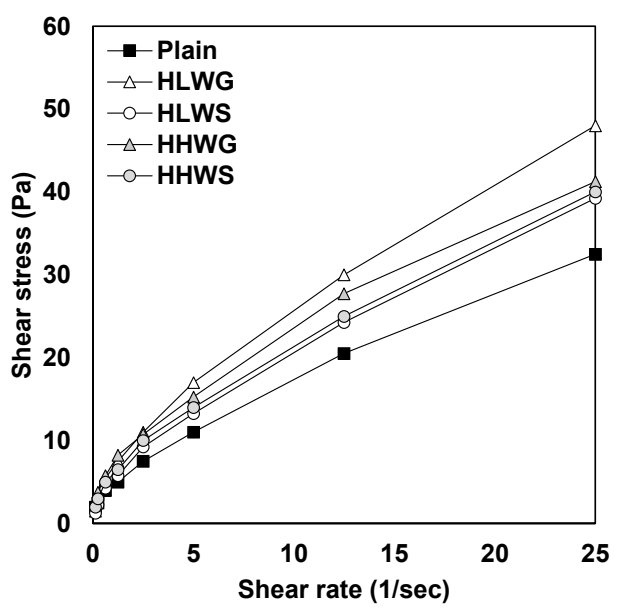

(c)

Figure 4. Consistency curves of fresh concrete added with NPCE, prepared by VMA combinations after $60 \mathrm{~min}$. (a) Combinations of one type of VMA only. (b) Combinations of two types of VMAs. (c) Combinations of three types of VMAs.

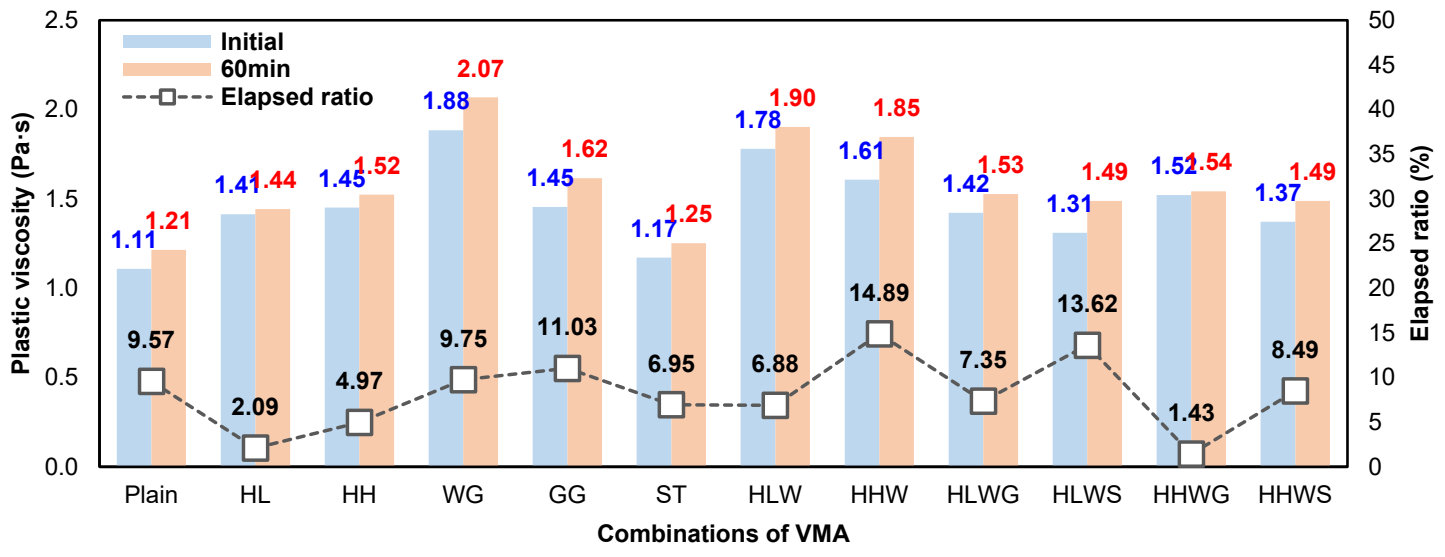

Figure 5. Plastic viscosity and elapsed ratio of fresh concrete by different combinations of VMAs. 


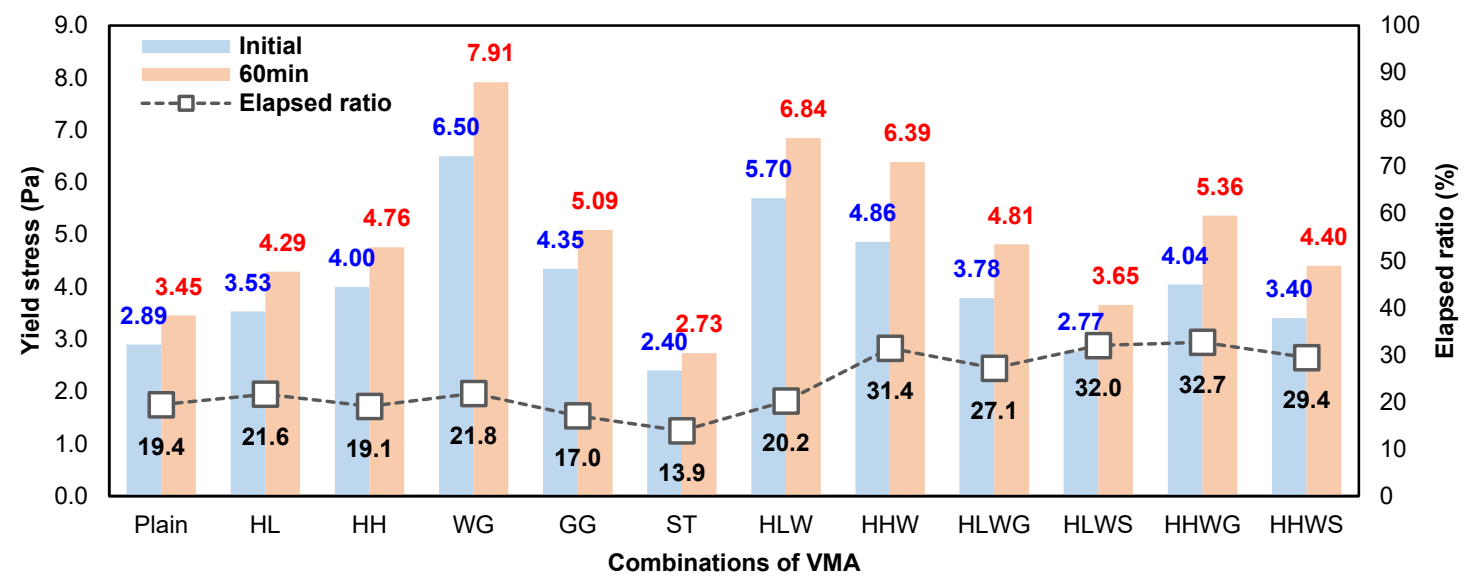

Figure 6. Yield stress and elapsed ratio of fresh concrete by different combinations of VMAs.

\subsection{Compressive Strength}

Figure 7 shows the compressive strength according to combinations of PCE and VMAs. Overall, the strength exceeds $24 \mathrm{MPa}$ at 28 days of curing duration for all types of mixes. With the addition of PCE (without VMA), the compressive strength was found to be at 13.6, 21.5 , and $30.9 \mathrm{MPa}$ after 3,7 , and 28 days of curing duration. Aside from this, PCE with WG showed the highest compressive strength when compared to other samples. In particular, WG provides a $17 \%$ higher compressive strength at 28 days, but the other combinations show a decrease of $4-20 \%$ in strength compared to the plain sample at 28 days. In particular, the addition of HPMC (HL and $\mathrm{HH}$ ) shows the greatest decrease in strength for Plain. The reasons for this are that HPMC has the potential to adsorb PCE, and it delays the cement hydration due to its effects on the precipitation of calcium hydroxide and water absorption. With the addition of PCE with two types of VMA, the two mixes show a similar compressive strength at 28 days. Due to the increase in HPMC from $0.3 \%$ to $0.6 \%$, HHW shows a $7 \%$ strength reduction compared to HLW at 3 days. It was considered that the characteristics of HPMC influenced the setting time and hydration process [44,45]. With the addition of PCE with three types of VMA, the compressive strength of HLWG and HHWG at 3 days and 28 days are the highest compared to HLWS and HHWS samples. The combination of HL or GG shows a higher compressive strength than the combination of HH or ST. This supposedly reflects each strength characteristic that is confirmed when only one type of VMA is added. In summary, it is shown that the unique characteristics of VMA are exhibited by and affect the compressive strength, according to the combinations of different types of VMAs.

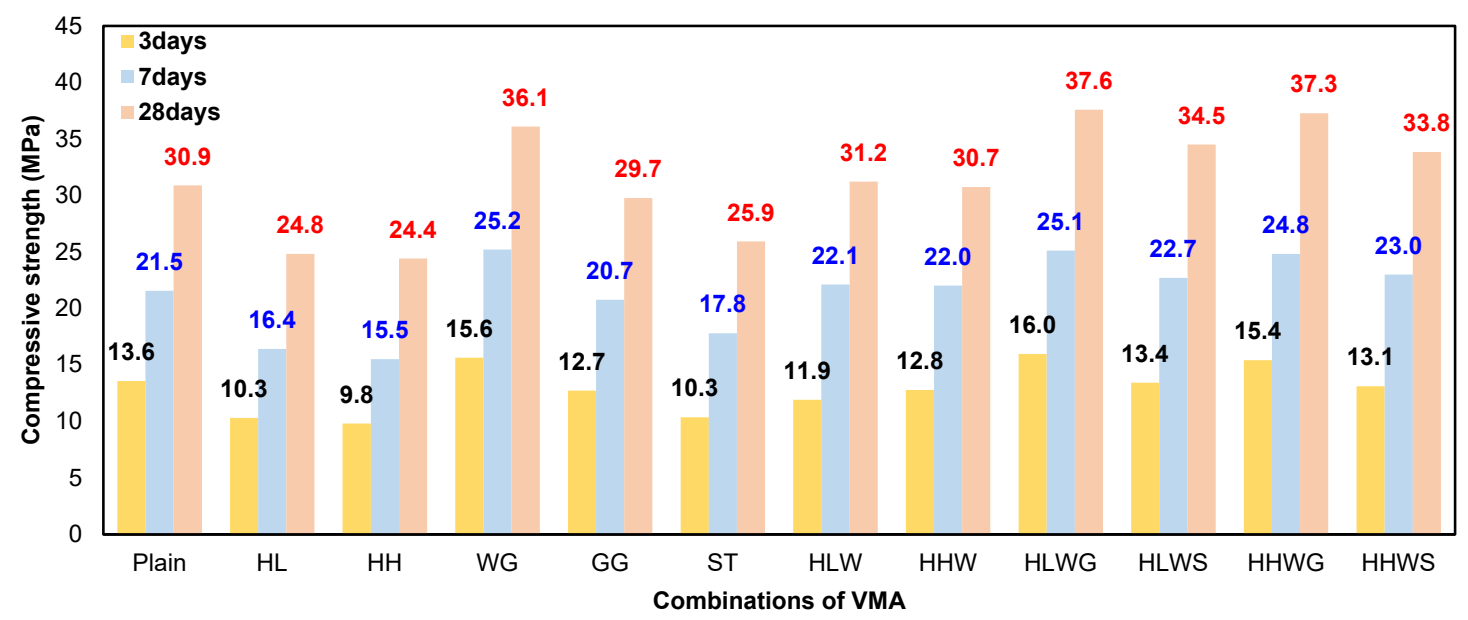

Figure 7. Compressive strength of hardened concrete by different combinations of VMAs. 


\section{Conclusions}

This study focused on the physical phenomena, such as fluidity, rheological properties, and compressive strength, of normal-strength, high-fluidity concrete (NSHFC) with a different type of polycarboxylate-based superplasticizer (NPCE):

(1) When the amount of HPMC increased from $0.3 \%$ to $0.6 \%$, the slump flow decreased due to the increase in the plastic viscosity of concrete. The elapsed ratio of concrete decreased due to the delay in the setting time of HPMC. Regardless of the amount and combinations of HPMC, ST had an effect on increasing fluidity and reducing the elapsed ratio, whereas WG had an effect on reducing fluidity and increasing the elapsed ratio. These results are similarly reflected in all combinations of VMAs.

(2) Adding VMA caused a higher plastic viscosity compared to the plain sample. The plastic viscosity and yield stress showed a proportional relationship, regardless of the combinations of VMA and the elapsed time. Moreover, the plastic viscosity and yield stress decreased when the slump flow increased, and increased when the slump flow is decreased. This showed an inverse relationship between the plastic viscosity or yield stress and the slump flow.

(3) The compressive strength at 28 days was found to be in the order of WG (36.1 $\mathrm{MPa})>\mathrm{GG}(29.7 \mathrm{MPa})>\mathrm{ST}(25.9 \mathrm{MPa})>\mathrm{HL}(24.8 \mathrm{MPa})>\mathrm{HH}(24.4 \mathrm{MPa})$, compared to when VMA was used alone. When two or more types of VMA were added, the unique characteristics of VMA were exhibited and affected the compressive strength according to the combinations of VMA.

(4) Using NPCE with VMA, it was possible to reduce the lack of fluidity and segregation, which were limited when using a polycarboxylate-based superplasticizer alone at low binders $\left(350 \mathrm{~kg} / \mathrm{m}^{3}\right)$. In conclusion, the combination of three types of VMA showed the best fluidity (slump flow 595 630 $\mathrm{mm}$ at initial) without any segregation and bleeding, and the compressive strength at 28 days was also the highest at 34-37 MPa. From these results, the combination of PCE $(2.0 \%)+$ HPMC $(0.3 \%)+$ WG $(0.1 \%)+$ ST $(0.1 \%)$ showed an $18 \%$ higher plastic viscosity than Plain and a $-4.4 \%$ lower yield stress than Plain. As a result, it was considered to have the best fluidity performance (slump flow $630 \mathrm{~mm}$ ) of NSHFC.

Author Contributions: Data curation, T.-W.K.; Formal analysis, T.-W.K., H.-M.Y., H.-S.L. and C.-B.Y.; Funding acquisition, H.-S.L.; Investigation, H.-M.Y. and H.-S.L.; Methodology, T.-W.K., H.-M.Y., H.-S.L. and C.-B.Y.; Supervision, H.-M.Y. and H.-S.L.; Writing-original draft, T.-W.K., H.-M.Y., H.-S.L. and C.-B.Y.; Writing-review and editing, T.-W.K., H.-M.Y., H.-S.L. and C.-B.Y. All authors have read and agreed to the published version of the manuscript.

Funding: This research received no external funding.

Institutional Review Board Statement: Not applicable.

Informed Consent Statement: Not applicable.

Data Availability Statement: The raw/processed data required to reproduce these findings cannot be shared at this time as the data also forms part of an ongoing study.

Acknowledgments: This research was supported by R\&D for businesses, suitable for small and medium-sized businesses and returning to Korea (S2304169), as well as the basic science research program through the National Research Foundation (NRF) of Korea funded by the Ministry of Science, ICT, and Future Planning (No. 2015R1A5A1037548).

Conflicts of Interest: All authors declare that there are no conflict of interest.

\section{References}

1. Ozawa, K.; Maekawa, K.; Okamura, H. Development of high performance concrete. J. Fac. Eng. Univ. Tokyo Ser. B 1992, 41, 381-439.

2. Chen, Y.; Veer, F.; Copuroglu, O. A critical review of 3D concrete printing as a low $\mathrm{CO}_{2}$ concrete approach. Heron 2017, 62, 167-194.

3. Safawi, M.I.; Iwaki, I.; Miura, T. A Study on the Applicability of Vibration in Fresh High-Fluidity Concrete. 2004. Available online: https://www.sciencedirect.com/science/article/abs/pii/S0008884604004867 (accessed on 16 November 2021). 
4. Shi, Y.-X.; Matsui, I.; Guo, Y.-J. A study on the effect of fine mineral powders with distinct vitreous contents on the fluidity and rheological properties of concrete. Cem. Concr. Res. 2004, 34, 1381-1387. [CrossRef]

5. Choi, Y.-W.; Chung, J.-S.; Moon, D.-J.; Shin, H.-C. A Study on Proportion of Normal-Strength Self-Compacting Concrete Using Ground Calcium Carbonate. J. Korean Soc. Civ. Eng. 2003, 23, 627-637.

6. Choi, Y.-W.; Moon, J.-H.; Eom, J.-H. Chloride Ion Penetration Properties of Normal Strength High-Fluidity Concrete Using Lime Stone Powder. J. Korea Inst. Struct. Maint. Insp. 2010, 14, 160-168.

7. Billberg, P. The effect of mineral and chemical admixtures on fine mortar rheology. Spec. Publ. 1997, 173, 301-320.

8. Wasserman, R.I. The performance of high-fluidity concrete for normal strength structures. Constr. Build. Mater. 2017, 133, 285-300. [CrossRef]

9. Pelisser, F.; Vieira, A.; Bernardin, A.M. Efficient self-compacting concrete with low cement consumption. J. Clean. Prod. 2018, 175, 324-332. [CrossRef]

10. Yammine, J.; Chaouche, M.; Guerinet, M.; Moranville, M.; Roussel, N. From ordinary rhelogy concrete to self compacting concrete: A transition between frictional and hydrodynamic interactions. Cem. Concr. Res. 2008, 38, 890-896. [CrossRef]

11. ACI PRC-237-07. Self-Consolidating Concrete. 2007. Available online: https://documents.pub/document/aci-237r-07-selfconsolidating-concrete-1.html (accessed on 16 November 2021).

12. Peng, Y.; Jacobsen, S. Influence of water/cement ratio, admixtures and filler on sedimentation and bleeding of cement paste. Cem. Concr. Res. 2013, 54, 133-142. [CrossRef]

13. Peng, Y.; Lauten, R.A.; Reknes, K.; Jacobsen, S. Bleeding and sedimentation of cement paste measured by hydrostatic pressure and Turbiscan. Cem. Concr. Compos. 2017, 76, 25-38. [CrossRef]

14. Tang, C.-W.; Yen, T.; Chang, C.-S.; Chen, K.-H. Optimizing mixture proportions for flowable high-performance concrete via rheology tests. Mater. J. 2001, 98, 493-502.

15. Assaad, J.; Khayat, K.H.; Daczko, J. Evaluation of static stability of self-consolidating concrete. Mater. J. 2004, 101, $207-215$.

16. Bilgil, A.; Ozturk, B.; Bilgil, H. A numerical approach to determine viscosity-dependent segregation in fresh concrete. Appl. Math. Comput. 2005, 162, 225-241. [CrossRef]

17. Winnefeld, F.; Becker, S.; Pakusch, J.; Götz, T. Effects of the molecular architecture of comb-shaped superplasticizers on their performance in cementitious systems. Cem. Concr. Compos. 2007, 29, 251-262. [CrossRef]

18. Yamada, K.; Takahashi, T.; Hanehara, S.; Matsuhisa, M. Effects of the chemical structure on the properties of polycarboxylate-type superplasticizer. Cem. Concr. Res. 2000, 30, 197-207. [CrossRef]

19. Palacios, M.; Flatt, R.J.; Puertas, F.; Sanchez-Herencia, A. Compatibility between polycarboxylate and viscosity-modifying admixtures in cement pastes. ACI Spec. Publ. 2012, 288, 29-42.

20. Jang, H.-O.; Jee, N.-Y. An experimental study on the mixing of normal strength and high-fluidity concrete using ground granulated blast furnace slag. J. Archit. Inst. Korea Struct. Constr. 2013, 29, 81-88.

21. Khayat, K.H. Viscosity-enhancing admixtures for cement-based materials-An overview. Cem. Concr. Compos. 1998, 20, 171-188 [CrossRef]

22. Rols, S.; Ambroise, J.; Pera, J. Effects of different viscosity agents on the properties of self-leveling concrete. Cem. Concr. Res. 1999, 29, 261-266. [CrossRef]

23. Lachemi, M.; Hossain, K.; Lambros, V.; Nkinamubanzi, P.-C.; Bouzoubaa, N. Performance of new viscosity modifying admixtures in enhancing the rheological properties of cement paste. Cem. Concr. Res. 2004, 34, 185-193. [CrossRef]

24. Leemann, A.; Winnefeld, F. The effect of viscosity modifying agents on mortar and concrete. Cem. Concr. Compos. 2007, 29, 341-349. [CrossRef]

25. Yen, T.; Tang, C.-W.; Chang, C.-S.; Chen, K.-H. Flow behaviour of high strength high-performance concrete. Cem. Concr. Compos. 1999, 21, 413-424. [CrossRef]

26. Zhang, Y.; Zhao, Q.; Liu, C.; Zhou, M. Properties comparison of mortars with welan gum or cellulose ether. Constr. Build. Mater. 2016, 102, 648-653. [CrossRef]

27. Ma, B.; Peng, Y.; Tan, H.; Jian, S.; Zhi, Z.; Guo, Y.; Qi, H.; Zhang, T.; He, X. Effect of hydroxypropyl-methyl cellulose ether on rheology of cement paste plasticized by polycarboxylate superplasticizer. Constr. Build. Mater. 2018, 160, 341-350. [CrossRef]

28. Sakata, N.; Maruyama, K.; Minami, M. Basic properties and effects of welan gum on self-consolidating concrete. In Production Methods and Workability of Concrete; CRC Press: Boca Raton, FL, USA, 2004; pp. 249-266.

29. Teng, L.; Zhu, J.; Khayat, K.H.; Liu, J. Effect of welan gum and nanoclay on thixotropy of UHPC. Cem. Concr. Res. 2020, 138, 106238. [CrossRef]

30. Govin, A.; Bartholin, M.-C.; Biasotti, B.; Giudici, M.; Langella, V.; Grosseau, P. Modification of water retention and rheological properties of fresh state cement-based mortars by guar gum derivatives. Constr. Build. Mater. 2016, 122, 772-780. [CrossRef]

31. Govin, A.; Bartholin, M.-C.; Schmidt, W.; Grosseau, P. Combination of superplasticizers with hydroxypropyl guar, effect on cement-paste properties. Constr. Build. Mater. 2019, 215, 595-604. [CrossRef]

32. Lee, D.K.; Shin, J.H.; Yoo, B.H.; Son, H.J.; Han, H.S. Development of specialized viscosity agent for high-fluidity concrete using normal binders. Korea Concr. Inst. 2019, 31, 337-338.

33. ASTM C150/C150 9M-20b. Standard Specification for Portland Cement; ASTM International: West Conshohocken, PA, USA, 2020; Available online: https://shop.bsigroup.com/products/standard-specification-for-portland-cement (accessed on 16 November 2021). 
34. KS L 5405. Fly Ash; Korean Standards Association: Seoul, Korea, 2018.

35. KS F 2563. Ground Granulated Blast_Furnace Slag for use in Concrete; Korean Standards Association: Seoul, Korea, 2018.

36. KS F 2527. Concrete Aggregate; Korean Standards Association: Seoul, Korea, 2020.

37. ASTM C39-21. Standard Test Method for Compressive Strength of Cylindrical Concrete Specimens; ASTM International: West Coshohocken, PA, USA, 2021.

38. KS F 2403. Standard Test Method for Making and Curing Concrete Specimens; Korean Standards Association: Seoul, Korea, 2019.

39. Plank, J.; Lummer, N.R.; Dugonjić-Bilić, F. Competitive adsorption between an AMPS ${ }^{\circledR}$-based fluid loss polymer and Welan gum biopolymer in oil well cement. J. Appl. Polym. Sci. 2010, 116, 2913-2919. [CrossRef]

40. Khayat, K.; Saric-Coric, M. Effect of Welan Gum SuperplasticizerCombinations on Properties of Cement Grouts. Spec. Publ. 2000, 195, 249-268.

41. Okamura, H.; Ouchi, M. Self-compacting concrete. J. Adv. Concr. Technol. 2003, 1, 5-15. [CrossRef]

42. Varela, H.; Barluenga, G.; Palomar, I. Influence of nanoclays on flowability and rheology of SCC pastes. Constr. Build. Mater. 2020, 243, 118285. [CrossRef]

43. Wallevik, J.E. Relationship between the Bingham parameters and slump. Cem. Concr. Res. 2006, 36, 1214-1221. [CrossRef]

44. Knapen, E.; Van Gemert, D. Cement hydration and microstructure formation in the presence of water-soluble polymers. Cem. Concr. Res. 2009, 39, 6-13. [CrossRef]

45. Figueiredo, S.C.; Çopuroğlu, O.; Schlangen, E. Effect of viscosity modifier admixture on Portland cement paste hydration and microstructure. Constr. Build. Mater. 2019, 212, 818-840. [CrossRef] 